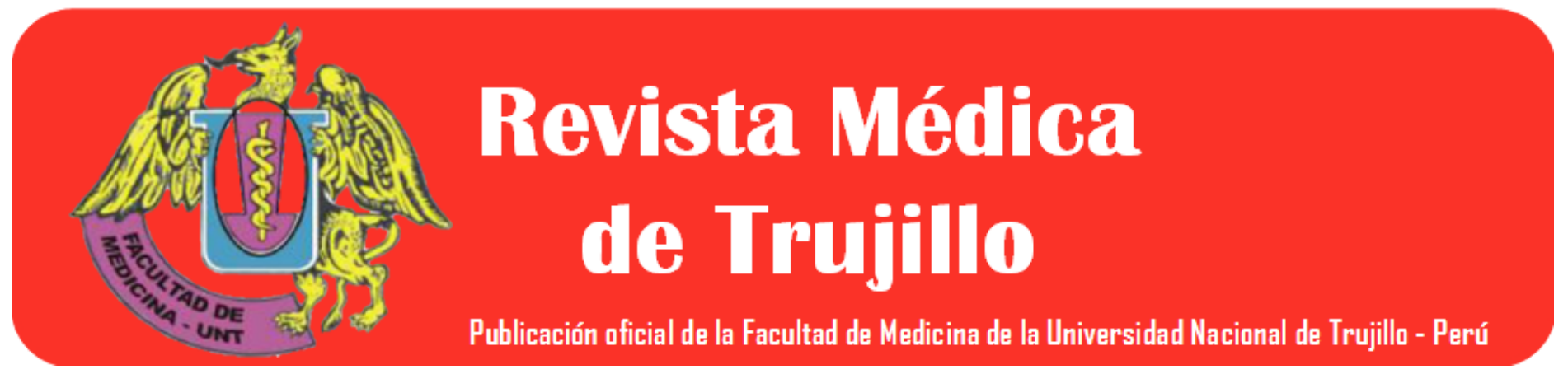

\title{
Imágenes en medicina
}

\section{Tomografía de tórax en un paciente con COVID-19}

\author{
Thorax CT scan of a COVID-19 patient
}

$$
\text { Jorge Arturo Rodríguez-Reyna }{ }^{1 a}
$$

1. Centro de Imágenes TOMONORTE a. Médico Radiólogo

\section{Correspondencia.}

Jarge Artura Radríguez Reyna

cordeiesu司hatmail.com

Recibido: 07/07/20

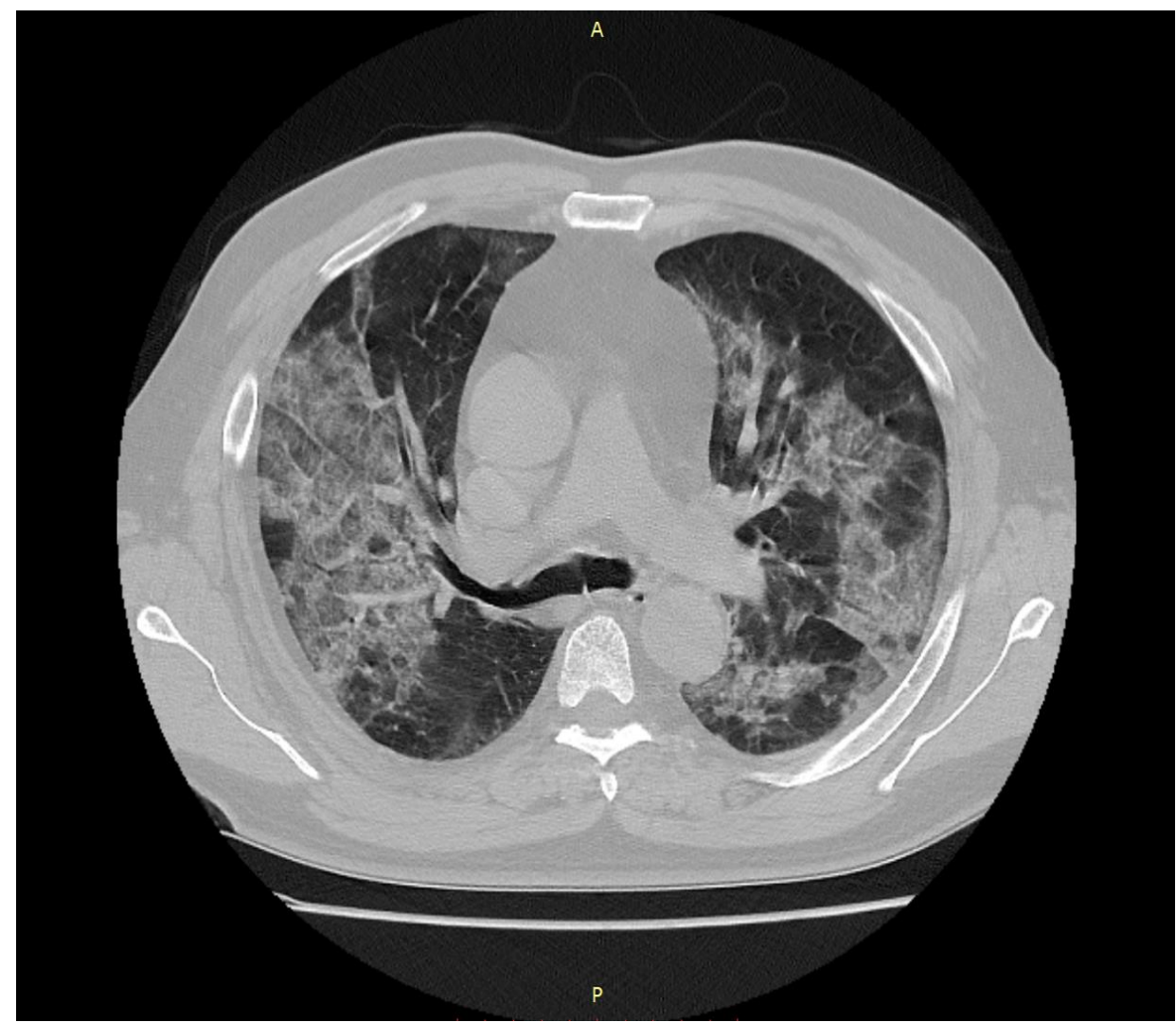




\section{Rodríguez-Reyna}

Paciente varón de 74 años, según familiar hace 10 empezó con malestar general, pico febriles y tos seca. no disnea. hace 4 días le realizan prueba rápida para covid siendo negativa, y hace 2 días le realizan $\mathrm{rx}$ de tórax hallando compromiso tenue alveolar parcheado en ambos campos pulmonares asociado a acentuación del intersticio. considerar signos de proceso inflamatorio pulmonar. se recomienda ampliar con tem de tórax para definir. También se evidencian fracturas no recientes entre el $6^{\circ}$ y $9^{\circ}$ arcos costales izquierdos. Hace 2 días cedió la fiebre. No presenta antecedentes de neumonia y tbc. Ulteriormente el paciente presentó empeoramiento del cuadro y dos semanas después se realizó nuevamente otra prueba rápida que resultó positiva. Falleció la semana siguiente.

\begin{tabular}{l}
\hline SCORE DE SEVERIDAD: \\
\hline $5 \%$ de compromiso $=1$ punto \\
$5 \%-25 \%$ de compromiso $=2$ puntos \\
$25 \%-50 \%$ de compromiso $=3$ puntos \\
$50 \%-75 \%$ de compromiso $=4$ puntos \\
$>75 \%$ de compromiso $=5$ puntos.
\end{tabular}

Tabulado por cada lóbulo, total 5 lóbulos Score máximo 25 puntos.

\section{DESCRIPCIÓN}

- Infiltrados pulmonares irregulares bilaterales, focales y difusos, en "vidrio esmerilado", algunos con patrón en "empedrado", de predominio posterior, con compromiso subpleural, posterior y basal, distribuidos en los 5 lóbulos, algunos con broncograma aéreo, asociados con escasas bandas parenquimales lineales, hallazgos compatibles con neumonía atípica probablemente viral. Índice de severidad: $15 / 25$.

\section{CONCLUSIÓN}

Infiltrados pulmonares bilaterales en "vidrio esmerilado" de predominio periférico, compatible con neumonía atípica. Indice de severidad: 15/25. Estadio pico. Las pruebas rápidas para anticuerpos SARS Covid 2 suelen dar una gran cantidad de falsos negativos, sobre todo en fases tempranas de la enfermedad. La tomografía de tórax demuestra ser un recuerso valioso para complementar el diagnóstico clínico y epidemiológico en tiempos de esta pandemia.

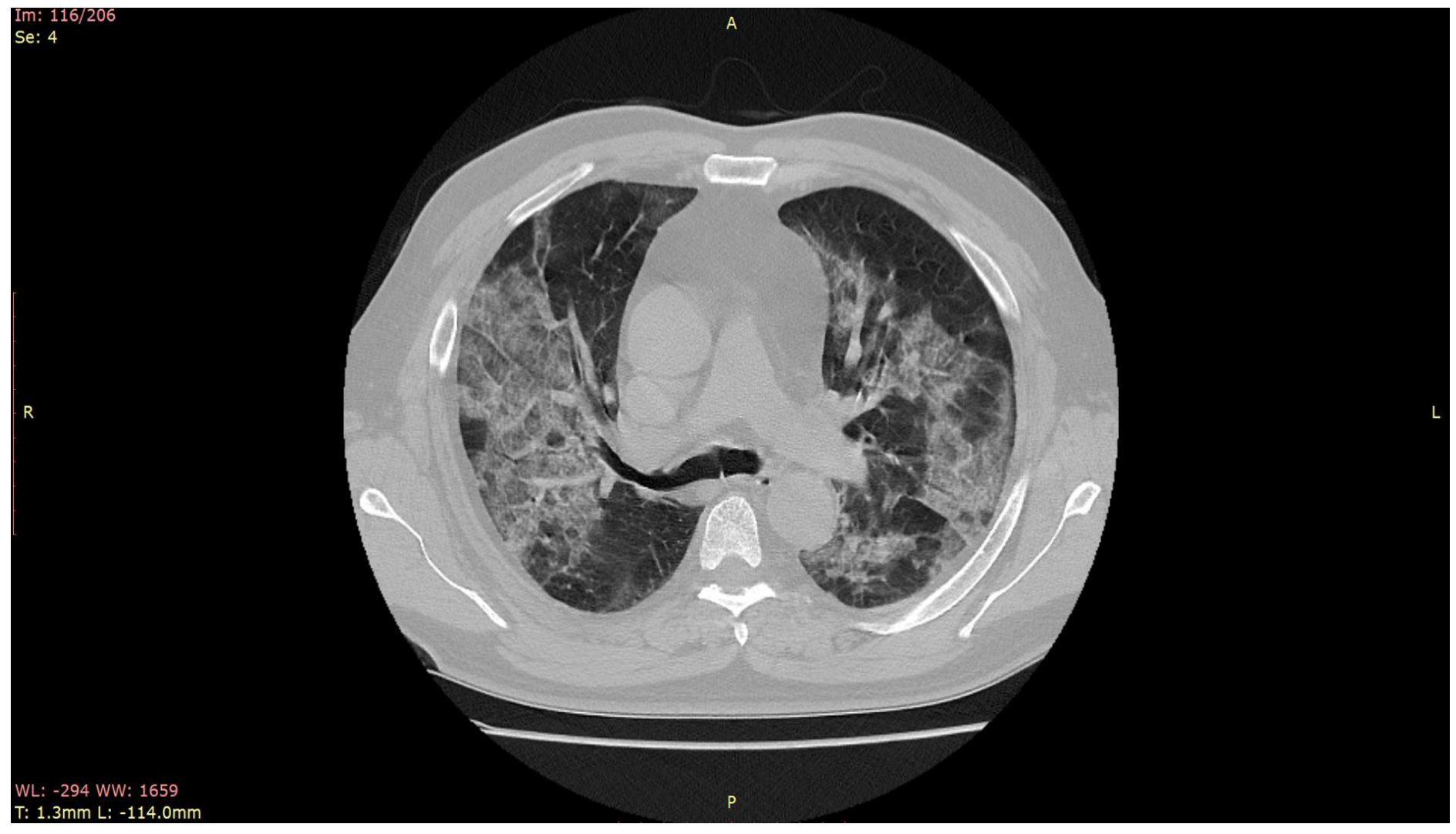



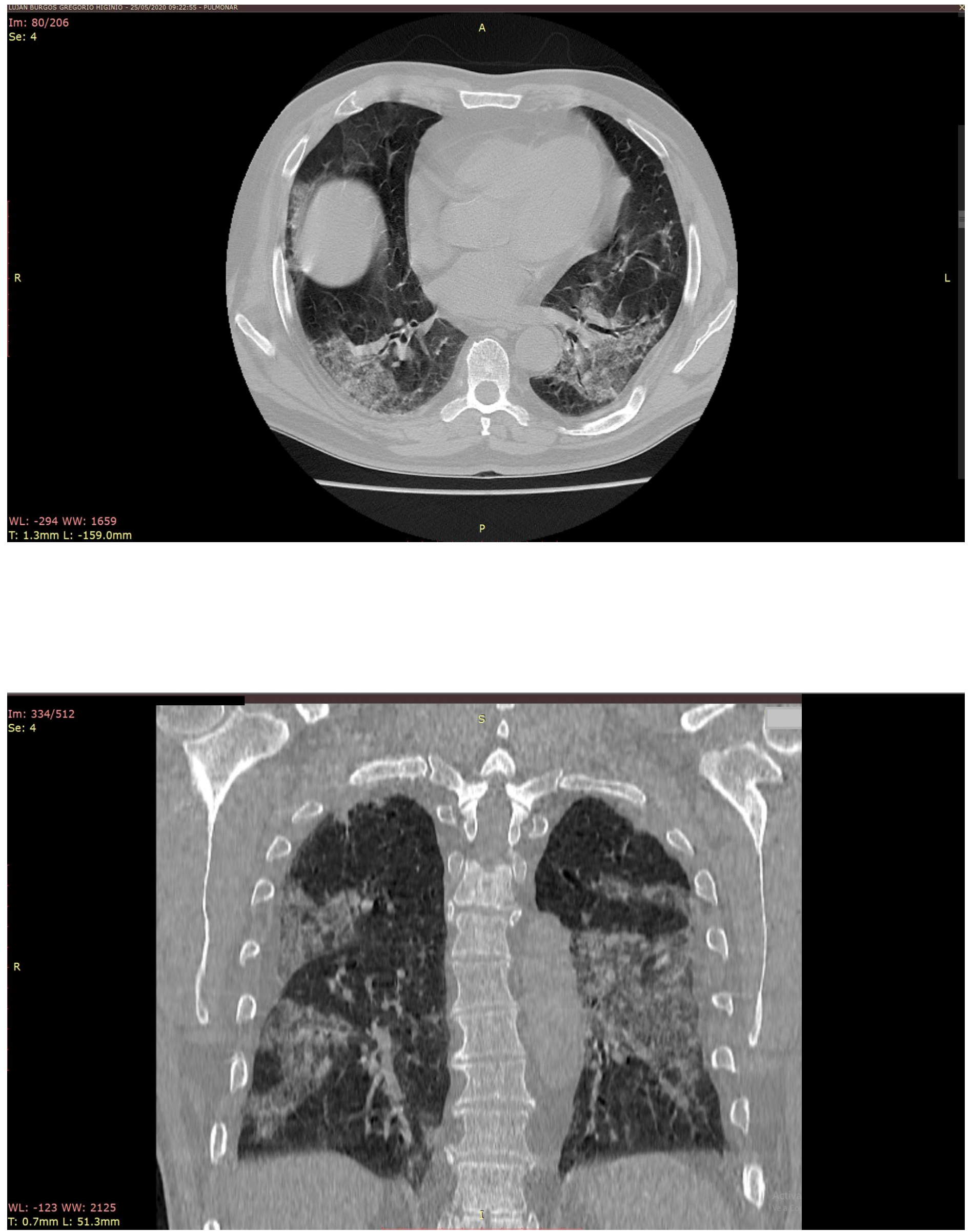


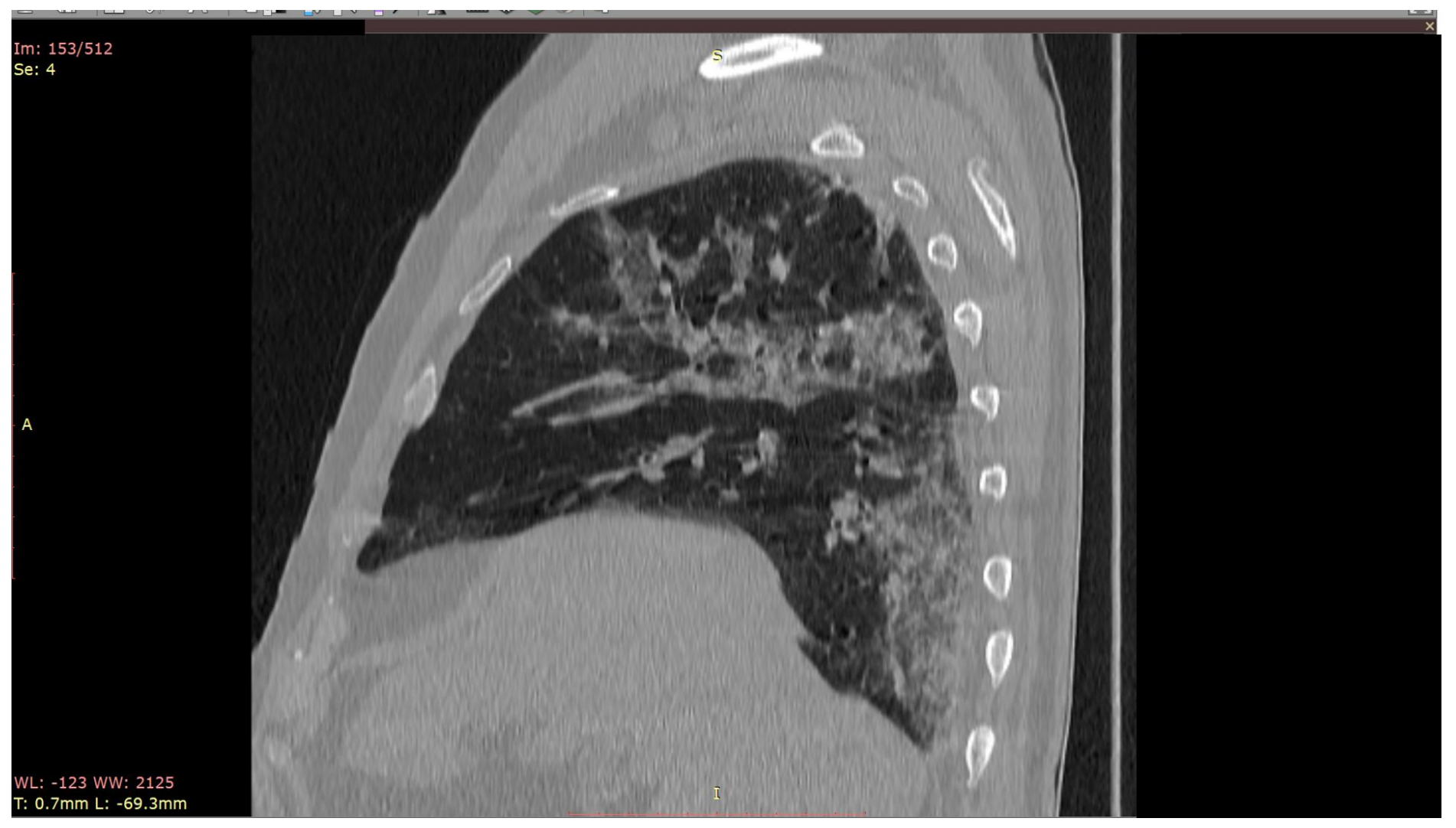

Citar como: Rodríguez-Reyna JA. Tomografía de tórax en un paciente con COVID-19. Rev méd Trujillo 2020;15(3):134-7 